This is a pre-publication version of the article accepted for publication: Kelan, E. K. (forthcoming) 'The Inclusive Leader, The Smart Strategist and The Forced Altruist: Subject Positions for Men as Gender Equality Partners', European Management Review

\title{
The Inclusive Leader, The Smart Strategist and The Forced Altruist: Subject Positions for Men as Gender Equality Partners
}

\begin{abstract}
This article explores how men are conceptualised as partners in gender equality processes in organisations against the backdrop of a postfeminist sensibility. Drawing on interviews that formed part of organisational ethnographies, the article highlights three subject positions that men are encouraged to adopt: the inclusive leader, the smart strategist, and the forced altruist. All three subject positions entail the construction of men as disadvantaged through a focus on women. While theorists of postfeminism have shown how women are made responsible for their own success and failure with structural gender inequalities being disavowed, the opposite logic seems to operate for men; if men do not succeed, it is due to unequal gender structures that favour women. Alternative subject positions could focus on making men's privilege visible or on that men who support gender equality might accelerate their careers. The article also shows that gender equality is still seen as a women's issue rather than an issue that concerns both women and men.
\end{abstract}

Keywords: discourse, feminism, gender, men, postfeminism

Running Title: Men as Gender Equality Partners 


\section{Introduction}

Men are increasingly called to action in regard to gender equality. The Canadian Prime Minister Justin Trudeau called himself a feminist (UN News Centre, 2016), the Financial Times (FT) (Hoyos and Rigby, 2015) published a list of the top ten male feminists, and Esquire magazine (Esquire, 2016) dedicated a special issue to men and feminism. However so far little is known about how men are conceptualised as partners in gender equality processes and how this relates to the current postfeminist commonsense (O'Neill, 2015; Rumens, 2017). Scholars of postfeminism have pointed out how current discourses of gender equality are characterised by strong individualisation, where individuals are expected to improve their own value and if they fail to do so, they have only themselves to blame (Adamson and Kelan, 2019; Baker and Kelan, 2018; Gill et al., 2017; Lewis et al., 2018). Postfeminism can best be understood as an analytical device, a sensibility or a discursive formation to understand the current patterning of culture (Gill, 2016) or in other words, how a 'commonsense' on gender equality (Gill et al., 2017) is created. With the recent popularisation of a specific kind of feminism (Rottenberg, 2014), postfeminism can be used as an analytical tool to understand the shifting and changing landscape of how gender inequality is being talked about. The question of how men are conceptualised as partners in organisational gender equality processes against the backdrop of postfeminism is thus an important one.

The article traces which subject positions are offered to men as partners in gender equality processes. A subject position draws on the idea that individuals are interpellated or 'hailed' by specific discourses (Althusser, 1971). Subject positions thus invite individuals to adopt a certain worldview and construct their identities in line with those worldviews (Davies and 
Harré, 1990; Edley, 2001a). Individuals are not free to take any subject position because cultural histories and power dynamics determine which positions can be adopted (Edley, 2001a). Discourses open a variety of subject positions, which might be taken on, rejected or negotiated by individuals. In this article, the focus is on which subject positions are opened in discourse and how they attempt to interpellate subjects, but not how individuals relate to these subject positions. In other words, the article explores how men are conceptualised as partners in gender equality processes but not how men take on those positions. The article starts by reviewing the literature on the contemporary subject positions that are opened for men in gender equality. The methodology and methods are then explained. The empirical part shows that three subject positions are opened for men as partners in gender equality processes at work. These three subject positions do not describe individual men but rather how men are interpellated in relation to gender equality in organisations. The findings are then theorised in the context of a postfeminist culture before a conclusion is offered. The article argues that while women have been constructed as in charge for their own career where structural barriers are less relevant, men are constructed as being hindered by structures that ought to create gender equality.

\section{'Male Feminists' and Postfeminism}

While the figure of the 'male feminist' has recently been brought up in the media, the role of men in changing systems and structures in organisations remains fairly unexplored. There is only very limited research on men in senior leadership and executive positions as change agents for gender equality (Kelan and Wratil, 2018; de Vries, 2015). The recent calls for men to become engaged in gender equality at work means that new subject positions for men as change agents are offered. Those subject positions will be closely related to current discourses of gender equality, which can be studied through postfeminism as an analytic 
device. While research on postfeminism has been shown that women are made responsible for their own success through individualisation, it can be expected that men are similarly made responsible for achieving gender equality through the creation of specific subject positions that speak to them. The aim of the article is thus to highlight which subject positions are offered for men in discourses on gender equality in organisations against the backdrop of postfeminism. For the purpose of this article, men as feminists are used as shorthand to refer to men engaged in gender equality.

While feminism refers to different and varied movements and theories on gender equality (Kemp and Squires, 1998), postfeminism is concerned with understanding the patterning of discourse around gender equality as cultural and social phenomenon (Gill et al., 2017). There are various different definitions of postfeminism (for a review, see Gill et al., 2017) and this article conceptualises postfeminism as a sensibility. Here, postfeminism does not denote an epistemological change, theoretical moving on or a backlash, but postfeminism becomes an analytical tool to understand the current social and cultural formations around gender. Analysts of postfeminism try to understand how a postfeminist common sense is established (Gill et al., 2017). Research in this vein has explored for instance how gender is understood in cultural and media workplaces (Gill et al., 2017; McRobbie, 2008; Scharff, 2015). Such research shows how current gender relations are intertwined with a discourse of choice and individualism, putting the individual in the driving seat to overcome any form of gender inequality by downplaying structural gender inequalities. This is often understood as a repudiation of feminism following the logic that if gender equality has already been achieved, there is no need for emancipatory discourses like feminism (Scharff, 2012). Feminism is thus often discursively 'pasted' or 'overed' (Kelan, 2009). Another important element of the postfeminist sensibility is that women are often constructed as advantaged; women are seen 
as having the right skills and attributes to succeed and everyone aims to promote more women, which means that this discourse allows little room to suggest that women might continue to be disadvantaged (Brown, 2016; Gill et al., 2017; Kelan, 2014). Such female advantage discourses could theoretically mean that men are disadvantaged now.

As men have recently been called into action on gender equality, this raises the question of how men are conceptualised as partners in organisational gender equality. Research on men and masculinities has been established for many decades (Anderson, 2007; Connell, 1995; Connell and Wood, 2005; Hearn, 1996, 2014; Kimmel, 1993). Research on men and masculinities in the work context has focused on the symbolic association of men with work and men's identities. Kanter (1977) discussed how those men reproduce themselves in their own image. Other research aimed at tackling the simultaneous invisibility of men, while acknowledging that men are the norm in organisations (Collinson and Hearn, 1994, 1996). Research in this vein has explored men in a variety of contexts: the shopfloor (Collinson, 1992), the factory (Salzinger, 2004), the financial services industry (Kerfoot and Knights, 1993) and also men as salesmen (Hodgson, 2003), engineers (Massey, 1996) and in nontraditional occupations (Cross and Bagilhole, 2002; Simpson, 2005). Cockburn (1991) shows how men actively try to keep women out of work and thus resist women's inclusion. Martin (2001) has analysed how men mobilise masculinity to exclude women. However showing how practices can change Ely and Meyerson (2010) highlight how men on oil platforms started to enact different notions of masculinity when an initiative to safety and effectiveness was introduced. However, while notions of masculinity can change, it is not clear if the workplaces as such became more gender equal. 
Men attempting to include women in the workplace is less well researched. A review of the literature has shown that practices of men doing gender are more common than practices of men undoing gender (Kelan, 2018). Research on change agents for gender equality has argued that senior leaders, many of whom are men, are well-served to use tempered radicalism and post-heroic leadership (Kelan and Wratil, 2018). De Vries (2015) suggests that men can be more effective change agents for gender equality, whereas women saw their ability to act as change agents curtailed by the fact that they were seen as having a selfinterest in promoting gender equality (see also van den Brink and Benschop, 2012). It is therefore men who 'undoubtedly appear well positioned to bring about change because of their positional power and the advantages conferred by their gender' (de Vries, 2015: 33). However, de Vries (2015) questions if those in power are ever able to deconstruct their own privilege. It has also been explored how men can become active on gender equality (Bluckert, 1989; Burke and Major, 2014; McAndrew, 1989; Ruth, 1989; Simmons, 1989). While men can become supporters of gender equality, it is often difficult to motivate them to do so (Bach, 2017; Bjørnholt, 2011; Pease, 2000). This is also related to the question if the construct of 'male feminist' is a possible identity for men. While Taylor identified as a strategic non-feminist (Tienari and Taylor, 2018), Tienari alongside others (Hearn, 2014; Kimmel, 2013) identified as a feminist man (Tienari and Taylor, 2018). Tienari (Tienari and Taylor, 2018) also acknowledges that identifying as a feminist man can be strange for women who themselves do not identify as feminists. This is an obvious overlap with postfeminism as Tienari (Tienari and Taylor, 2018) points out. This resonates with the need to analyse 'how men are located in post-feminist (sic) culture' (O’Neill, 2015, p. 115). Similarly, Rumens (2017) calls for a greater focus on how postfeminism, men and masculinities interact. This means that exploring how men are positioned as partners of gender equality in organisations against the backdrop of postfeminism becomes an important question. 
While research has regularly explored men in organisations, it is currently not well understood which subject positions are offered to men in gender equality efforts. The article therefore represents a foray into understanding which subject positions are offered to men in organisational gender equality against the backdrop of postfeminism. The article contributes an understanding to the literature how dynamics of postfeminism operate differently for men and for women.

\section{Methodology and Methods}

In order to explore the subject positions opened for men in gender equality processes, this research draws on 23 interviews with professionals in the Global North, specially advanced economies in Northern Europe. The three organisations varied in terms of location (Austria, Germany, United Kingdom) and industry (Accounting, Broadcasting and Chemicals), and were not selected for representativeness. Instead, all three organisations had engaged in gender equality efforts and were not only willing to provide access for the research but also identified men who were engaged in gender equality efforts by, for instance, being part of the gender equality network in the organisation. I job-shadowed three men, which generated 130 hours of observation, which inform the interviews, but are not discussed in great detail in this article. The interviewees were the men themselves as well as co-workers (more junior, peer and more senior). The research participants were part of a group of professional workers earning a good income but did not belong to a wealth elite. I decided that to understand the subject positions opened to men in gender equality processes, it would be important to speak to men and women, and 11 interviewees were men and 12 were women. I conducted seven interviews in Accounting, nine in Broadcasting, and seven in Chemicals. The interviews 
included questions about the interviewees themselves, as well as their perceptions of gender equality and particularly men's roles in gender equality in the organisation and beyond.

The interviews were conducted in a discourse analytic tradition (Potter and Wetherell, 1987). Discourse analysis in this form is particularly concerned with identifying interpretative repertoires, which are units of sense-making regularly drawn upon to construct a common sense (Wetherell and Potter, 1988). Discourse analysis has been used by scholars on postfeminism to identify ways in which the common sense on gender is articulated (see for instance the studies on which this article is based (Gill et al., 2017)). Those interpretative repertoires also open up subject positions that individuals are invited to adopt (Edley, 2001b). In this research, the main interest was on which subject positions are opened for men in gender equality processes. The research therefore identified the interpretative repertoires that were used by different members of the organisation to talk about men and gender equality. Out of the interpretative repertoires, I created subject positions for each organisation that aim to interpellate individuals. Those do not respond to individual men but are rather figures that members of the organisations constructed for men through their talk. The research shows which subject positions are opened but does not engage with how these subject positions are adopted, rejected or re-constituted.

The average length of the interviews was 47 minutes, which excluded the initial discussion and also conversations after the digital recorder had been switched off. The interviews were recorded and transcribed fully by a transcription service using a version of the Jefferson system $^{1}$. I proofread the interview transcripts for accuracy. The interviews were then coded by a research assistant and myself using Dedoose. The first round of coding followed the interview questions and a largely thematic analysis. The interviews were not analysed 
organisation-by-organisation but rather by themes that were discussed. The second round of coding focused more closely on how men are conceptualised in the context of gender equality. The final round of coding focused on interpretative repertoires.

The three interpretative repertoires identified through the analysis mapped onto the three organisations. This is rather unusual because subject positions often vary significantly, even within an organisational context. In theory, there are a variety of subject positions that can be mobilised, and in practice, many individuals shift between subject positions, even within the same interview. However, in this research, the subject positions seemed closely aligned with the organisations, even though there was some overlap between organisations. Although none of the organisations had developed initiatives to engage men in gender equality specifically, this indicates that how men are conceptualised in gender equality efforts is aligned to the organisational culture. How men in gender equality was conceptualised was contingent on a broader understanding of why gender equality is important for the organisations, which related to the context in which the organisation operates, as well as its history and organisational culture. In addition, the national culture in which the organisations operated could have influenced how men in gender equality are conceptualised. Rather than seeing this diversity as a disadvantage, for this research, it is advantageous that these different subject positions are presented because it allows covering a wide array of potential subject positions. The variety of subject positions also speaks to the fact that how men are conceptualised in gender equality processes is still nascent; there might be specific subject positions that are drawn upon more in an organisation or in a country, but there does not seem to be a collective common sense way of accounting for men in gender equality efforts. Otherwise, a standard subject position might have been traceable across the different contexts. While the subject positions that emerged through the analysis were distinguishable, there is some overlap 
between them, which is common in discourse analysis. For instance, the first two subject positions discussed show some overlap, whereas the third is fairly stand-alone. This could be due to either organisational or country-specific factors, but no definite answer on why these subject positions were drawn upon can be offered. As the aim of the article is to show how men are conceptualised as partners in organisational gender equality, showing differences and similarities in subject positions opened for men is desirable and useful. Thereby, it is shown how certain subject positions appear more popular in specific contexts and are thus favoured over alternative subject positions that could be drawn upon. While it is sometimes possible to show that individuals have knowledge of other subject positions and would thus be competent to use them but chose not to (Chomsky, 1965), there were few such instances in the present material. The reason for this might be that many people might simply not have been confronted with different subject positions for men in gender equality processes and thus lack the competence to articulate them. They might jump to the first subject position that makes sense to them. It should also be noted that the interview extracts presented for Broadcasting and Chemicals are my own translation. The subject positions do not reflect the individual's position nor how they negotiate and adopt those subject positions.

\section{Subject Positions for Men as Gender Equality Partners}

Through the empirical analysis, I identified three subject positions for men in gender equality processes: the inclusive leader, the smart strategist, and the forced altruist. These three constructions are subject positions that emerged from how men and women talked about men as partners for gender equality in the respective organisations. As these are subject positions, they do not map onto specific individuals and I do not explore how individual men are negotiating and taking up those subject positions. There is some overlap between the subject positions but those subject positions were nevertheless analytically distinguishable. The 
empirical analysis will thus follow the organisation-by-organisation structure to show how the specific subject positions were opened and how they partly overlapped.

\section{The Inclusive Leader}

In the first organisation, the subject position for men as partners in gender equality processes was that of the inclusive leader. It entailed educating individuals about their gender biases to help them to become better - more inclusive - leaders. Individual leaders are here given the responsibility to manage towards inclusion. Inclusion is commonly talked about in organisations often in combination with diversity. Where diversity focuses on differences between individuals, inclusion means that individuals can fully contribute to the organisational functioning (Roberson, 2006). The terminology of inclusive leadership deployed in Accounting situates the responsibility of creating inclusion in leaders. This means that leaders, many of whom are men, are required to ensure that their actions are inclusive. This in turn will help the organisation to fulfil its business mission in a better way.

Alexander explains:

Alexander: My big thing is inclusive leadership (...) for me inclusive leadership is people taking personal responsibility for building diverse teams. (...) we know that naturally (.) we would choose to hang out with people who are like us, because of implicit bias and subconscious bias, and implicit association; when we look at our friendship group or our colleagues or our partner or where we live, we choose sameness, but inclusive leadership is consciously choosing different and consciously choosing to include that difference in our teams. 
Inclusive leadership is here defined as giving individuals in the organisation the responsibility to implement inclusion practices. How this inclusive leadership is supposed to be performed is illustrated by referring to building diverse teams where individual biases need to be overcome to avoid people appointing in their own image. This refers to recruitment bias and appointing in one's own image, which Kanter (1977) talked about, and which can be challenged through a range of behavioural practices such as joint rather than individual evaluations against future performance (Bohnet et al., 2016). Alexander indicated to me that he is basing much of his rationale on the work of Bohnet, which might explain his focus on recruitment bias. For Alexander, inclusive leadership then means making sure that you pick people for your team that are not like you. The responsibility for managing gender equality is relegated to individual decision-makers. As many of those decision-makers are going to be men, it can be concluded that inclusive leadership is mainly targeted at men who make decisions.

Alexander provides an example for how this might look:

Alexander: If I look at somebody that I've coached (...), it's a really nice guy who just does not have the language or the life experience to know how to interact with people that are very different from them. You know, his life experience of women is his second wife who's not his intellectual equal, is his female PA and it's not really an equal female professional. So, it's basically trying to reconfigure for him HE (.) that (.) women as equal as professionals can add to his professional experience by bringing a different thought process to the table and by challenging his thought process.

The construction of men that emerges here is that they need to broaden their horizon by understanding their own biases to allow them to make different decisions. 
Another example where this inclusive leadership is displayed also relates to recruitment.

Audrey: Where do we look for people that we recruit at graduate level? Do we tend to go to certain schools and universities? Well, actually then, we are tending to perpetuate the same flow into those institutions that we are drawing our populations from, so we need to think more widely. (...) So, everything that I individually or that we collectively do that is more inclusive will help us to achieve that objective. And whilst my own part of that is going to be tiny, it does mean that if we are, when I'm looking at CVs, if we're interviewing a group of candidates, applying those thought processes about, okay, so have I got some unconscious bias going on here? If I have, recognise it and park it.

While Audrey does not talk about men specifically, she illustrates how inclusive leadership is practised in the organisation where everyone has to check their biases to avoid recruiting in their own image.

Alexander: I now see a lot of pushback from men (...) who haven't been promoted or have been told they are not going to be promoted and are basically thinking it's because they are a man or because we are favouring women or somehow (...) But I think they (the senior leaders) are sensitive to the noises that they hear from (.) particularly men at you know, middle management, who feel now that somehow they are being disadvantaged.

While men are encouraged to be inclusive leaders, Alexander alludes to some resistance from men in middle management positions who feel that they are disadvantaged. 
In Accounting, men can support gender equality by constructing them as inclusive leaders. The organisation tries to ensure that decision-makers change their perceptions through coaching and bias awareness training. This is a personal approach that allows individuals to recognise their own blindspots through empathising with others. It is men who need to learn that women can be equal partners at work. By changing decision-makers, it is presumed that they will eventually change their decisions and become an inclusive leader who can run the business better. Some men also appear to feel disadvantaged by the focus on gender equality.

\section{The Smart Strategist}

While the subject position of the inclusive leader centres largely on blindspots in decisionmaking such as around recruitment and how individuals can self-correct for that bias, the subject position opened in Chemicals focused also on improving business processes but stressed strategy. The smart strategist sees the business value of gender equality, but while in Accounting, the business value lies in changing behavioural interactions, the business value for Chemicals seems to lie in developing a more strategic and, one might say, abstract conceptualisation of why gender equality matters for business. Another difference to Accounting, where gender equality fell under the umbrella of diversity and inclusion, is that gender equality was treated as a stand-alone issue in Chemicals. The current gender equality effort at Chemicals was started through a range of discussion groups where the opportunities of developing gender as a strategy from a talent and customer perspective were discussed. The discussion groups were initiated by a consultant who was hired to foster greater gender equality in the organisation and who led sessions for the leaders in the organisation. The consultant also trained organisational members to lead the discussion groups. In that way, the impetus for gender change was cascaded through different levels of the organisation. The 
group discussions also had the effect that the conceptualisation of gender equality used in those strategic conversations permeated the organisation and were the main frame of reference to articulate thinking around gender equality. As one of the interviewees, Christoph, discusses how those discussion groups were designed for leaders, he talks about the fact that ' 9 out of 10 ' leaders attended those sessions without being forced. While these discussion groups are constructed as a success, Cordula offers a slightly different perspective: Cordula: When we had the discussion groups, some of the (male) managers brought the Myers-Briggs Assessment [MBTI], the personality assessment to document that they are already diverse. One is introverted, the other is extroverted. That is really what happened. This is why we decided that we talk about gender. The managers also talked about the laboured phrase, 'it is about diversity of thought'. (...) Well, it is correct that a homogenous group already has a certain diversity of thought. However, using this as an excuse does not advance the topic.

Cordula takes issue with using the MBTI to show diversity to justify why this organisation talks about gender specifically. The resistance to the smart strategist that Cordula describes denies and rejects the need to change because people are already diverse.

During my fieldwork in the organisation, I was able to observe how gender equality was integrated into the personal performance evaluation.

Christoph: When the new CEO came on board, who made it [gender equality] his thing, the opportunity arose. The executive committee decided that goals around the issue should form part of the performance evaluations. (...) In the end, we decided to focus on training and to define concrete aims around that. 
Fostering gender equality is thus imperative from the top where individual managers are incentivised through performance evaluation.

However, during my observation of the gender equality group meeting, there was a tangible disappointment of how the unique opportunity to integrate gender equality into individual performance evaluation has turned out. There was top level support from the CEO to include gender equality goals into performance evaluation. While the overall CEO seems keen on that, the local management team of the local organisation insisted on specific goals, which eventually meant that every employee had to undergo online training on gender equality. This is easy to measure and can be ticked off, but the gender equality working group felt that this was a missed opportunity. Instead of having individual conversations about how a person can make a contribution to gender equality in the organisation and to define individual goals in this context, the outcome of the process was that everyone has to do standardised gender equality training online. There was a sense of frustration that was articulated in the gender equality working group meeting. As one participant said, it was a unique opportunity to do something transformational around gender equality that might not come around again. Rather than becoming a truly smart strategist who can figure out how gender equality matters in a given context, a generic training is offered, which potentially is less effective. One might understand this as a form of resistance of how leaders in the local organisation were watering down the impetus from the CEO.

Gender equality is conceptualised as a strategy in this organisation and much of the change initiatives are framed around this. The discussion groups that were conducted in the organisation were presented as generic but designed to speak particularly to men and to involve them in gender equality. Men are encouraged to be smart strategists on gender 
equality, who through their strategic vision, develop an awareness that gender is important from a customer and talent perspective. However, men either resist that by claiming that they are already diverse or they simply have to do an online training to fulfill their duty on gender equality. While Accounting focuses on behavioural interventions such as to help avoiding recruitment bias, at Chemicals, the discussions centred more on realising the importance of gender for strategic decisions around markets. While both approaches ultimately seek to improve the running of the business, the translation into practice differed in both settings and opened different subject positions to men. The inclusive leader considered diversity in everyday decision-making, while the smart strategist realises the importance of gender for strategic choices.

\section{The Forced Altruist}

The context of the third organisation as a public organisation means that it has to comply with a legal mandate to create gender equality. While a business imperative around making the organisation more profitable was paramount in the other organisations, at Media, the work around gender equality was driven by a social justice perspective. The legal mandate, together with the responsibility toward society, triggered the gender equality initiatives in the organisation, which in turn structured the subject position opened for men in gender equality: the forced altruist.

Benjamin explains three elements through which gender equality is embedded in Broadcasting: the equal opportunities officer, the gender equality commission, and the task force women. The former two are legally institutionalised, whereas the task force women is a lobbying group and there are of course intersections between the three groups. This legally- 
mandated framework around gender equality was constructed as relating to the public nature of the organisation. In order to strive for the greater good, men have to sacrifice something.

Bjorn: Men support other men. Men's networks work for them. (...) Men are now not specifically advanced because of equal opportunities. That does not help us (men). (.) The opposite is true actually. If there is a quota for women and I (as a man) apply, I am likely to be disadvantaged. (...). If I am disadvantaged as a man in a specific application process, then I do not mind if equality moved forward or backward. I am personally disadvantaged. (...). It sounds like a special sacrifice, like with dispossession. If you are the person to make the sacrifice, you are not going to be happy. Unless you are able to see the greater good. It is a really important point to communicate it to men who are disadvantaged through the efforts to achieve gender equality that considering the bigger picture, they will also profit.

Bjorn suggests here that men need to sacrifice their own career for the greater good to have gender equality in the organisation, but he is aware that men will not like the personal disadvantage for the greater good.

A similar sentiment was voiced by Bastian:

Bastian: If one wants to increase the percentage of women and if one wants to do that systematically and if you want to have success, then you will overdo it from time to time. And then the careers of individual men fall by the wayside. One has to be open about that. One can say 'well you helped to support the bigger picture, because women's careers fell by the wayside for the last thirty years and now men's careers fall by the wayside'. But that does, does not help the individual. (...) Dying for the higher 
cause, nobody will understand that (...) Men will ask 'why am I disadvantaged, cannot get the higher position, even though I am BETTER qualified?' The answer is because women were disadvantaged for thirty years. The man will respond 'I understand that, share it, regret it but why do I have to suffer for it?'

Bastian mobilises a similar point to Bjorn requiring men to sacrifice their career for gender equality and fairness overall, but he also states that this is a hard sell for most men because they have to give up their individual career. However, Bastian adds a more specific illustration where the man is better qualified than the woman but the woman gets the job for the sake of gender equality. The forced altruist position seems to run against ideas of merit (Humbert et al., 2019) and is therefore seen as unpalatable. This shows how the forced altruist subject position is difficult to inhabit for men because it requires personal sacrifice and because it seems to disregard merit.

Bianca: If I had a wish, I would want that men but also some women start their actual thinking to their espoused values. This way of thinking is not widely shared. Women are advanced when individuals are either forced or when they expect a personal benefit.

Bianca here explains that individuals often pretend to support gender equality in theory but are not doing that in practice, which requires force or incentive to change that.

Asked why men recruit and promote women, Birte responds:

Birte: I think he [the generic man] has to. I don't believe he does it voluntarily. I think there is now a bigger focus on employing women but otherwise men would have just 
continued the way they are. Without external pressure, it would be like fifty or thirty years ago.

The subject positioned opened to men in this organisation is one intertwined with force. Men are forced to change due to external pressures and this change involves their personal sacrifice.

Bianca: More power for women means less power for men. (.) That does not happen voluntarily. (...) It has to do with loss of power, yes. It is uncomfortable. It has to do with changing the culture. Why would anyone do that voluntarily?

Bianca suggests that engaging in gender equality means a loss of power and one has to be forced to give up power.

The forced altruist subject position constructs men as needing to give up power for the greater good and recognises that men might not do that voluntary and thus need some force. This subject position expects men to make a personal sacrifice and to disregard merit by not being promoted to allow women to advance. However, the focus on force indicates that this subject position is possibly not one that many men will voluntarily inhabit. As a public organisation, Broadcasting's social responsibility and its legal mandate influenced how gender equality and men within it were positioned. Unlike the other two organisations where business rationales were in the foreground, at Broadcasting, the social case was paramount and structured how men were positioned as a forced altruist in gender equality.

\section{Discussion}


The aim of the article was to analyse which subject positions are offered for men in gender equality processes against the backdrop of postfeminism. While men are regularly addressed to become active on gender equality in popular discourse, it can first be established that the organisational discourses that directly address men to become active on gender equality were missing. The address was much more indirect through almost gender-neutral subject positions that everyone can potentially inhabit. It is also notable that all organisations drew on different subject positions that men were invited to adopt. The inclusive leader was someone who understood biases in decision-making and eradicates them by developing greater empathy for people who are different and by recruiting diverse individuals. The smart strategist also followed the business logic of improving processes by recognising that women are customers and talent. Men were invited to have discussions about gender as a strategy and their performance was evaluated based on gender-related goals, although that seems to equate to completing online training. While the business case dominated in the first two organisations, how the business case was conceptualised was different: at Accounting, the emphasis was on changing behaviour, whereas at Chemicals, the focus centred on thinking about women in terms of strategy. The final organisation was distinctly different because it recurred to the social case in that the forced altruist subject position invited men to see the greater good and accept that women might be promoted ahead of them. However, it was acknowledged that for many men, giving up their own career to advance women might be less appealing.

The subject positions contain an appeal to the individual and offer the idea that by adopting certain practices, individuals can transform themselves into the organisationally desired subject; in this case, the inclusive leader, the smart strategist, and the force altruist. These subject positions are aligned with how gender equality is conceptualised in the organisation 
as either a way to increase profit in respect to the inclusive leader and the smart strategist or as a way to show responsibility in society in the case of the forced altruist. They share an individualised appeal in common where the individual is in charge to make changes (Gill et al., 2017). Theorists of postfeminism have pointed out that individualisation is a key ingredient of contemporary thinking on gender where women are expected to transform themselves into the right type of woman by, for instance, being confident (Gill and Orgad, 2016). If a woman fails to radiate confidence, she only has herself to blame for her lack of professional success (Gill and Orgad, 2016).

While the subject positions that call on women to transform themselves are largely left unchallenged in mainstream discourses (Gill and Orgad, 2016), it is notable that the subject positions that try to create gender equal practices by engaging men are disputed, questioned and ultimately rendered less effective by interviewees. In the forced altruist position, it is suggested that men will not act in accordance with the greater good by giving up their career in favour of women. In regard to the smart strategist subject position, it was suggested that men resist change by either claiming that they are already diverse or by transforming gender equality into a tick box exercise. The inclusive leader subject position entailed that men feel disadvantaged. The subject positions offered to men therefore construct men as potentially disadvantaged through the focus on gender equality.

It is notable that other points of challenge such as that men simply have to put up with greater competition for roles because they are now competing with women are left unarticulated. The consequence of the subject position is that if men fail to have a career, it is because the system now appears titled towards women, which mirrors the female advantage component 
of the postfeminist sensibility at work (Gill et al., 2017). Rather than appealing to men to develop more confidence to survive the intensified competition for roles now that women compete for them, men fail because the system works against them. This is an inversion of the common argument that postfeminists have analysed, where systematic gender inequalities are acknowledged and the individual woman is encouraged to push through those barriers; if a woman fails, she fails because she did not push hard enough or did not develop enough confidence (Gill and Orgad, 2016). Conversely, if a man fails to have a career, it is due to gender equality working against him. This shows how the subject positions offered to men and women differ substantially when analysed through postfeminism as an analytic device.

There are two counter discourses that could be developed to challenge this discursive logic. First, helping men to realise their privilege and that they are profiting from a system that is skewed toward them. Second, it might be possible to suggest that if men engage in practices that create gender equality within the organisation, this should be rewarded as part of the performance evaluation (similar to what was attempted in Chemicals but which was watered down). Men can position themselves as the desired worker by becoming active on gender equality. Then, not their gender, but their practices would be central to their career advancement. Both approaches would challenge the idea that the system is now stacked in favour of women and that men will struggle to have a career.

\section{Conclusion}

The current postfeminist sensibility not only seems to entail that feminism is referenced as desirable but it is also constructed as something that men can and should get involved in. However, prior research has pointed out that how men are located in a postfeminist culture 
has not been explored (O’Neill, 2015; Rumens, 2017). This article aimed to highlight which subject positions are offered to men in gender equality efforts within a postfeminist culture, namely, the inclusive leader, the smart strategist, and the forced altruist. The first two approaches aim at including women due to business reasons, while the third aims to create social fairness. The article shows how the three subject positions were resisted in the organisations by constructing men as structurally disadvantaged through the focus on women. The logic entails that if men are not successful, it is because women are now the desired workers. This echoes the contemporary common sense on the female advantage, which analysts of postfeminism have highlighted (Gill et al., 2017). While analysts of postfeminism have shown how women are encouraged to empower themselves to be successful, the opposite dynamic seems to be at play in regard to men. While the three subject positions aim to individualise men to take action on gender equality, men are effectively constructed as systematically disadvantaged due to the focus on gender equality. The consequences of the postfeminist climate on gender equality are thus gendered: women are encouraged to improve themselves and if they do not advance their career, they only have themselves to blame; men are encouraged to be more gender equal but this focus of gender equality is simultaneously the reason why men do not advance. The article has suggested that counter discourses of how men who do gender equality well might be promoted or how men can realise their sustained privilege in the gender system could be strengthened. The way in which men are conceptualised as partners in gender equality means that gender equality is still seen as a women's issue rather than an issue that affects women and men.

While this article aimed to understand the subject positions that are offered to men in gender equality efforts, the focus on subject positions can in itself be seen as a limitation. Further research might explore what men are actually doing to support gender equality in 
organisations. Such research could add to the research on men as change agents (Kelan, 2018; Kelan and Wratil, 2018; de Vries, 2015) and show how men negotiate, take up and inhabit those subject positions. The research is also limited due to the fact of who was interviewed and observed, because the research largely focused on those in middle management. It would also be beneficial to shed light on the different hierarchical levels through which men can unfold their potential to support gender equality in professional life and if a different potential for change exists for senior leaders, middle managers and front line staff. The article is also limited by taking place in three organisations in three countries in Northern Europe, and other organisational and country settings might lead to different subject positions. The present article suggests that men who support gender equality might enjoy a career acceleration; this could be explored in further research to show under which conditions this might be the case. For instance, it might be that white men might enjoy a career acceleration but not all men. In the same vein, it would also be fascinating to explore how men's involvement in gender equality is related to class, 'race' and ableism. Further studies on how men in their private life can support gender equality as some studies have already started to do (Bach, 2017; Bjørnholt, 2011; Nentwich, 2008). Such research would offer a refinement to understanding the complex connections between men and postfeminism that this article has highlighted that the subject positions offered to men in regard to gender equality focus on structural inequalities in favour of women, whereas a similar account targeted at women would stress how women are self-responsible for their success.

For practitioners working towards gender equality in organisations, the research shows that while engaging men as gender equality partners can be a useful strategy, practitioners have to carefully consider which unintended consequences these constructions can bring. The three subject positions analysed in this article might provide an indication of what such unintended 
consequences might be. Alternative subject positions that could be stressed are, for instance, that men have to realise their own privilege imbued on them by the historic and contemporary gender system or how being an engaged partner in gender equality can have career accelerating effects. Debunking privilege and common misconceptions around gender alongside practical advice on what men can do might be useful here. It would also be important to ensure that practitioners stress that gender is not just a women's problem but that gender equality affects both women and men. The article shows how the contemporary postfeminist climate constructs men as disadvantaged due to a focus on gender equality, while simultaneously positioning the gender equality within the realm of women rather than men and glossing over the sustained gender inequalities that women experience in the workplace.

\section{References}

Adamson, M. and Kelan, E.K. (2019), “'Female Heroes’: Celebrity Executives as Postfeminist Role Models", British Journal of Management.

Althusser, L. (1971), "Lenin and Philosophy and Other Essays”, New Left Review, Vol. 1964 No. May, pp. 1-169.

Anderson, E. (2007), "Inclusive Masculinity in a Fraternal Setting”, Men and Masculinities, pp. 1-17.

Bach, A.S. (2017), “The Ambiguous Construction of Nondominant Masculinity”, Men and Masculinities.

Baker, D.T. and Kelan, E.K. (2018), "Splitting and blaming: The psychic life of neoliberal executive women", Human Relations, available at:https://doi.org/10.1177/0018726718772010.

Bjørnholt, M. (2011), "How men became the local agents of change towards gender 
equality”, Journal of Gender Studies, Vol. 20 No. 1, pp. 3-18.

Bluckert, P. (1989), “Courage and Spark: Discovering new meanings and expressions of leadership by men”, Equal Opportunities International, Vol. 8 No. 1, pp. 21-24.

Bohnet, I., van Geen, A. and Bazerman, M. (2016), "When Performance Trumps Gender Bias: Joint vs. Separate Evaluation”, Management Science, Vol. 62 No. 5, pp. 12251234.

van den Brink, M. and Benschop, Y. (2012), "Gender practices in the construction of academic excellence: Sheep with five legs”, Organization, Vol. 19 No. 4, pp. 507-524. Brown, S.E. (2016), There's Never Been A Better Time To Be a Woman? Gendered Discourses on the Route to the Boardroom, King's College London.

Burke, R.J. and Major, D.A. (2014), Gender in Organizations: Are Men Allies or Adversaries to Women's Career Advancement?, Edgar Elgar, Cheltenham.

Chomsky, N. (1965), Aspects of the Theory of Syntax, M. I. T. Press, Cambridge (Mass).

Cockburn, C. (1991), In the Way of Women: Men's Resistance to Sex Equality in Organizations, Macmillan, London.

Collinson, D. (1992), Managing the Shopfloor: Subjectivity, Masculinity, and Workplace Culture, W. de Gruyter, Berlin.

Collinson, D. and Hearn, J. (1994), "Naming Men as Men: Implications for Work, Organization and Management", Gender, Work and Organization, Vol. 1 No. 1, pp. $2-$ 22.

Collinson, D. and Hearn, J. (1996), “Men as Managers, Managers as Men: Critical Perspectives on Men, Masculinities and Management", Sage, London.

Connell, R.W. (1995), Masculinities, Polity, Cambridge.

Connell, R.W. and Wood, J. (2005), “Globalization and Business Masculinities”, Men and Masculinities, Vol. 7 No. 4, pp. 347-364. 
Cross, S. and Bagilhole, B. (2002), "Girls' Jobs for the Boys? Men, Masculinity and Nontraditional Occupations", Gender, Work and Organization, Vol. 9 No. 2, pp. 204-226.

Davies, B. and Harré, R. (1990), “Positioning: The Discursive Production of Selves”, Journal of Theory of Social Behaviour, Vol. 20 No. 1, pp. 43-65.

Edley, N. (2001a), “Analysing Masculinity: interpretive Repertoires, Ideolgical Dilemmas and Subject Positions", Discourse as Data: A Guide for Analysis, pp. 189-228.

Edley, N. (2001b), “Analysing Masculinity: Interpretative Repertoires, Ideological Dilemmas and Subject Positions", in Wetherell, M., Taylor, S. and Yates, S. (Eds.), Discourse as Data: A Guide for Analysis, Sage, London, pp. 189-228.

Ely, R.J. and Meyerson, D.E. (2010), “An organizational approach to undoing gender: The unlikely case of offshore oil platforms", Research in Organizational Behavior, Vol. 30, pp. 3-34.

Esquire. (2016), "Special Issue: Women and Men - We Need To Talk”, April.

Gill, R. (2016), "Post-postfeminism?: new feminist visibilities in postfeminist times Introduction: feminism, postfeminism and generation", Vol. 16 No. 4, pp. 610-630.

Gill, R., Kelan, E.K. and Scharff, C.M. (2017), “A Postfeminist Sensibility at Work”, Gender, Work \& Organization, Vol. 24 No. 3, pp. 226-244.

Gill, R. and Orgad, S. (2016), “The Confidence Cult(ure)”, Australian Feminist Studies, Vol. 30 No. 2015, pp. 324-344.

Hearn, J. (1996), "Deconstructing the Dominant: Making the One(s) the Other(s)", Organization, Vol. 3 No. 4, pp. 611-626.

Hearn, J. (2014), “On men, organizations and intersectionality: Personal, working, political and theoretical reflections (or how organization studies met profeminism)", Equality Diversity and Inclusion, Vol. 33 No. 5, pp. 414-428.

Hodgson, D. (2003), “'Taking it like a man’: Masculinity, Subjection and Resistance in the 
Selling of Life Assurance”, Gender, Work and Organization, Vol. 10 No. 1, pp. 1-21.

Hoyos, C. and Rigby, R. (2015), "FT's top 10 male feminists help women to the top",

Financial Times, p. 15 September.

Humbert, A.L., Kelan, E.K. and van den Brink, M. (2019), “The Perils of Gender Beliefs for Men Leaders as Change Agents for Gender Equality”, European Management Review, p. forthcoming.

Kanter, R.M. (1977), Men and Women of the Corporation, Basic Books, New York.

Kelan, E.K. (2009), “Gender Fatigue - The Ideological Dilemma of Gender Neutrality and Discrimination in Organisations", Canadian Journal of Administrative Sciences, Vol. 26 No. 3, pp. 197-210.

Kelan, E.K. (2014), "From Biological Clocks to Unspeakable Inequalities: The Intersectional Positioning of Young Professionals", British Journal of Management, Vol. 25 No. 4, pp. $790-804$.

Kelan, E.K. (2018), “Men Doing and Undoing Gender at Work: A Review and Research Agenda", International Journal of Management Reviews, Vol. 20 No. 2, pp. 544-558.

Kelan, E.K. and Wratil, P. (2018), "Post-heroic Leadership, Tempered Radicalism and Senior Leaders as Change Agents for Gender Equality", European Management Review, Vol. 15 No. 1 , pp. 5-18.

Kemp, S. and Squires, J. (1998), Feminisms, Oxford University Press, Oxford.

Kerfoot, D. and Knights, D. (1993), “Management, Masculinity and Manipulation: From Paternalism to Corporate Strategy in Financial Services in Britain”, Journal of Management Studies, Vol. 30 No. 4, pp. 659-677.

Kimmel, M.S. (1993), “Invisible masculinity”, Society, Vol. 30 No. 6, pp. 28-35.

Kimmel, M.S. (2013), Angry White Men: American Masculinity at the End of an Era, Nation Book, New York. 
Lewis, P., Benschop, Y. and Simpson, R. (2018), Postfeminism and Organization, Routledge, New York (NY).

Martin, P.Y. (2001), “'Mobilizing Masculinity’: Women’s Experiences of Men at Work”, Organization, Vol. 8 No. 4, pp. 587-618.

Massey, D. (1996), “Masculinity, Dualism and High Technology”, in Duncan, N. (Ed.), Body Space: Destabilising Geographies of Gender and Sexuality, Routledge, London, pp. $109-126$.

McAndrew, B. (1989), “Men's leadership - Power, vision and values”, Equal Opportunities International, Vol. 8 No. 1, pp. 12-15.

McRobbie, A. (2008), The Aftermath of Feminism: Gender, Culture and Social Change, Sage, London.

Nentwich, J.C. (2008), "New Fathers and Mothers as Gender Troublemakers? Exploring Discursive Constructions of Heterosexual Parenthood and their Subversive Potential", Feminism \& Psychology, Vol. 18 No. 2, pp. 207-230.

O’Neill, R. (2015), “Whither Critical Masculinity Studies? Notes on Inclusive Masculinity Theory, Postfeminism, and Sexual Politics", Men and Masculinities, SAGE PublicationsSage CA: Los Angeles, CA, Vol. 18 No. 1, pp. 100-120.

Pease, B. (2000), Recreating Men - Postmodern Masculinity in Politics, Sage, London.

Potter, J. and Wetherell, M. (1987), Discourse and Social Psychology: Beyond Attitudes and Behaviour, Sage, London.

Roberson, Q.M. (2006), "Disentangling the Meanings of Diversity and Inclusion in Organizations", Group and Organization Management, Vol. 31 No. 2, pp. 212-235.

Rottenberg, C. (2014), “Happiness and the Liberal Imagination: How Superwoman Became Balanced", Feminist Studies, Vol. 40 No. 1, pp. 144-168.

Rumens, N. (2017), "Postfeminism, Men, Masculinities and Work: A Research Agenda for 
Gender and Organization Studies Scholars”, Gender, Work \& Organization, Vol. 24 No. 3, pp. 245-259.

Ruth, S. (1989), “Leadership, Men Equality”, Equal Opportunities International, Vol. 8 No. 1, pp. 25-28.

Salzinger, L. (2004), "Revealing the unmarked: Finding masculinity in a global factory", Ethnography, Vol. 5 No. 1, pp. 5-27.

Scharff, C. (2012), Repudiating Feminism, Ashgate, Farnham.

Scharff, C. (2015), "Blowing your own trumpet: exploring the gendered dynamics of selfpromotion in the classical music profession", The Sociological Review, Vol. 63 No. S1, pp. $97-112$.

Simmons, M. (1989), “Creating a new men's leadership: Developing a theory and practice”, Equal Opportunities International, Vol. 8 No. 1, pp. 16-20.

Simpson, R. (2005), “Men in Non-Traditional Occupations: Career Entry, Career Orientation and Experience of Role Strain”, Gender, Work and Organization, Vol. 12 No. 4, pp. $363-380$.

Tienari, J. and Taylor, S. (2018), "Feminism and men: Ambivalent space for acting up", Organization, pp. 1-13.

UN News Centre. (2016), “UN Women chief, Canadian Prime Minister spotlight need to build global movement for gender equality", available at: http://www.un.org/apps/news/story.asp?NewsID=53462\#.V8beARS8GCh.

de Vries, J.A. (2015), “Champions of gender equality: Female and male executives as leaders of gender change", Equality, Diversity and Inclusion: An International Journal, Vol. 34 No. 1, pp. 21-36.

Wetherell, M. and Potter, J. (1988), “Discourse analysis and the identification of interpretative repertoires", in Antaki, C. (Ed.), Analysing Everyday Explanation - A 
Case Book of Methods, Sage, London, pp. 168-183.

${ }^{1}$ The transcription system is an adapted and simplified version of the Jefferson system: (.) is a short notable pause, [text] transcriber clarification on unclear parts of tape, (...) material deliberately omitted, '...' direct speech reported by interviewee.

Acknowledgement

The article is based on material collected as part a British Academy Mid-Career Fellowship [MD130085]. Due to the ethically sensitive nature of the research, no participants consented to their data being retained or shared. I would like to thank the anonymous reviewers and the editors of the special issue for their valuable feedback. Kimberly Dark provided invaluable comments on early draft versions of this article. I would also like to thank Patricia Wratil for helping to code the material as well as Alison Collins and Lesley Cuandu for proof reading earlier version of the article. 